\title{
Recent Developments in the Quantification and Regulation of Air Emissions from Animal Feeding Operations
}

\author{
Tarah Heinzen
}

Published online: 21 January 2015

(C) Springer International Publishing AG 2015

\begin{abstract}
Animal feeding operations (AFOs) emit various air pollutants, including ammonia, hydrogen sulfide, particulate matter, volatile organic compounds, methane, and nitrous oxide. Several of these pollutants are regulated under federal clean air statutes, yet AFOs have largely escaped regulation under these laws because of challenges in accurately estimating the rate and quantity of emissions from various types of livestock operations. Recent Environmental Protection Agency (EPA) efforts to collect emissions data, develop an emissions model capable of estimating emissions at AFOs nationwide, and establish emissions estimating methodologies for certain key livestock air pollutants suffered from design flaws and omitted pollutants of concern. Moreover, this process seems to have stalled, delaying other regulatory reforms needed to increase transparency and increase regulation of these facilities. Until EPA establishes these methodologies, significant AFO pollution regulation under the Clean Air Act or emissions reporting statutes will be very difficult to achieve, and the public health and environmental impacts of these emissions will continue unabated.
\end{abstract}

Keywords AFO - Air emission $\cdot$ EPA $\cdot$ Ammonia $\cdot$ PM . Greenhouse gas $\cdot$ NAEMS $\cdot$ CAA $\cdot$ EPCRA

\section{Introduction}

Animal feeding operations (AFOs) concentrate large numbers of livestock and their waste, keeping animals in confinement

This article is part of the Topical Collection on Food, Health, and the Environment

T. Heinzen $(\triangle)$

6918 6th Street NW, Washington, DC 20012, USA

e-mail: Tarah.heinzen@gmail.com buildings or feedlots without access to pasture. Over the past several decades, AFOs have become the nation's dominant method of livestock production [1]. These facilities emit a large suite of air pollutants - including ammonia, hydrogen sulfide, fine particulates, volatile organic compounds (VOCs), and greenhouse gases - from animal confinement areas, waste storage areas, and waste application fields [2].

AFO emissions expose several populations, both directly and indirectly. AFO workers who spend time inside animal confinement facilities and around waste and feed storage areas are consistently exposed to the highest concentrations of air emissions, but nearby rural communities can also be exposed to emissions from AFOs, as well as the application of AFO wastes on cropland. These exposures can vary significantly depending on wind direction, weather conditions, and waste handling practices at the AFO. The odors associated with these emissions can significantly decrease rural quality of life and property values $[3,4]$.

These emitted pollutants have been associated with numerous adverse public health and environmental impacts (Table 1). Ammonia gas is associated with respiratory symptoms, re-deposits to add nitrogen to nutrient-enriched surface waters, and reacts readily with oxides of nitrogen and sulfur to form fine particulate matter (PM), which, in turn can induce respiratory symptoms, heart attacks, premature death, and regional haze [5, 6]. Hydrogen sulfide harms quality of life in rural communities because of its rotten egg odor [2]. Researchers have identified numerous VOCs in AFO air emissions. Some of these VOCs, such as methanol, are also listed hazardous air pollutants regulated under Section 112 of the Clean Air Act (CAA) [7]. In the presence of sunlight, VOCs, such as benzene and methanol, contribute to ground-level ozone, which leads to respiratory symptoms, eye irritation, and damage to plant health [8]. AFOs also emit greenhouse gases - most notably, methane and nitrous oxide [9]. It is estimated that methane and nitrous oxide have 62 and 275 times 
Table 1 Air pollutants associated with animal feeding operations (AFOs) and significant impacts

\begin{tabular}{|c|c|}
\hline Pollutant & Impacts \\
\hline Ammonia & $\begin{array}{l}\text { - Respiratory and eye irritant } \\
\text { - } \mathrm{PM}_{2.5} \text { precursor } \\
\text { - Re-deposits to contribute to surface water } \\
\quad \text { eutrophication }\end{array}$ \\
\hline Hydrogen sulfide & $\begin{array}{l}\text { - Respiratory and eye irritant } \\
\text { - Asphyxiant; fatal at high concentrations }\end{array}$ \\
\hline Particulate matter & $\begin{array}{l}\text { - Respiratory and cardiovascular disease, } \\
\text { including asthma, bronchitis, and } \\
\text { premature death } \\
\text { - Regional haze }\end{array}$ \\
\hline Volatile organic compounds & $\begin{array}{l}\text { - Ozone and } \mathrm{PM}_{2.5} \text { precursors } \\
\text { - Some CAA-listed hazardous air pollutants } \\
\text { - Some known human carcinogens }\end{array}$ \\
\hline Greenhouse gases & $\begin{array}{l}\text { - Methane: } 62 \text { times the } 20 \text {-year warming } \\
\text { potential of } \mathrm{CO}_{2} \\
\text { - Nitrous oxide: } 275 \text { times the } 20 \text {-year } \\
\text { warming potential of } \mathrm{CO}_{2}\end{array}$ \\
\hline
\end{tabular}

$C A A$ Clean Air Act, $P M_{2.5}$ particulate matter 2.5 microns in diameter or smaller

the global warming potential of carbon dioxide, respectively, when their heat trapping effects are compared over a 20 -year period [9].

Because of these documented human health threats, the US Environmental Protection Agency (EPA) has established health exposure levels and ambient air quality standards for some of these emissions. EPA's Integrated Risk Information System (IRIS) assesses the health risk from exposure to various contaminants and has issued toxicological profiles for hundreds of chemicals, including ammonia and hydrogen sulfide. In 2012, EPA proposed an updated reference concentration (RfC) for chronic ammonia exposure, setting $0.3 \mathrm{mg} / \mathrm{m}^{3}$ as a safe long-term inhalation exposure level. This proposal would increase the ammonia RfC from $0.1 \mathrm{mg} / \mathrm{m}^{3}$, reflecting a smaller uncertainty factor due to additional studies since EPA issued the previous assessment [10]. The chronic inhalation $\mathrm{RfC}$ for hydrogen sulfide is $0.002 \mathrm{mg} / \mathrm{m}^{3}$ [11]. The RfCs are set at levels meant to account for existing uncertainty as to the health effects of chronic exposure to a certain chemical in isolation, but they do not separately account for the health effects of mixed exposures, such as the suite of chemicals found in AFO emissions [10, 11].

Recent studies of AFO air emissions support the argument that they may pose a public health hazard, and EPA action to better quantify them and thereby enable appropriate regulation is warranted. One 2014 study used agricultural ammonia emissions modeling to calculate that ammonia emissions linked to food exports alone - approximately $13 \%$ of all agricultural emissions and $11 \%$ of total US ammonia emissions - contribute to premature mortality from PM 2.5 microns in diameter or smaller $\left(\mathrm{PM}_{2.5}\right)$ at a public health cost of $\$ 36$ billion per year [6]. Recent research also affirms the important role livestock production plays in greenhouse gas production. The United Nations Food and Agriculture Organization estimates that, considering emissions due to feed production and transport, as well as direct emissions, livestock contribute $14.5 \%$ of global anthropogenic greenhouse gas emissions [12]. Direct emissions due to enteric fermentation and manure management have been estimated to be responsible for the majority of these emissions [12]. A recent analysis of the relative resource costs of various US livestock products found that US livestock production is responsible for about $5 \%$ of this country's greenhouse gas emissions [13].

Although some of these pollutants are currently regulated under the CAA and other federal statutes, challenges in quantifying the emissions of these pollutants, along with industry opposition to regulation, have hindered efforts to regulate AFOs under federal air pollution statutes [14]. As a result, they remain essentially unregulated.

This paper provides an overview of federal regulation of AFO air emissions, summarizing applicable requirements under the CAA, the Comprehensive Environmental Response, Compensation, and Liability Act (CERCLA, commonly known as Superfund), and the Emergency Planning and Community Right-to-Know Act (EPCRA). It then describes EPA's efforts to develop emissions estimating methodologies (EEMs) for key pollutants emitted by AFOs, by studying emissions at AFOs in several states over 2 years and beginning to analyze the data obtained, as well as related developments in the regulation of AFO emissions.

\section{Federal Clean Air Laws}

The three primary environmental statutes that apply to AFO air emissions are the CAA, CERCLA, and EPCRA. CERCLA and EPCRA both contain emissions reporting requirements for pollutants designated as hazardous or extremely hazardous, respectively, requiring emitters to report all air releases that exceed statutory threshold reportable quantities (RQs) to federal, state, and local emergency response authorities [15]. Ammonia and hydrogen sulfide are included in these lists of chemicals, and each has an RQ of 100 pounds per day [16].

Both statutes allow reduced reporting requirements for "continuous" releases, defined under CERCLA as emissions stable in quantity and rate [15]. EPA regulations further explain that continuous releases are routine and incidental to normal operation, and that facilities must separately report statistically significant increases in emissions. The facility bears the burden of demonstrating that its releases are continuous to qualify for limited reporting, which requires only an initial report and a follow-up report after 1 year [16]. EPCRA 
then makes these reports publicly available [17]. However, researchers who recently reviewed the availability of AFO reports submitted in states in and near the Chesapeake Bay watershed found that only four of seven states had any reports available, and those reports represented only $15 \%$ of AFOs. Most of the reports lacked basic information, such as the substance released and the estimated quantity released [18].

The CAA has several pollution control programs and regulations that may apply to certain AFO emissions. The criteria pollutant program establishes the National Ambient Air Quality Standards (NAAQS). The NAAQS are ambient concentration limits for common air pollutants and are set at levels protective of public health, with a margin of safety meant to protect sensitive populations and to protect public welfare [19]. The CAA defines public welfare broadly, including impacts on soils, water, vegetation, animals, wildlife, visibility, climate, property damage, and personal comfort and wellbeing; it also includes impacts due to a pollutant's transformation, conversion, or combination with other air pollutants [20]. The criteria pollutants include PM 10 microns in diameter or smaller $\left(\mathrm{PM}_{10}\right)$, with more stringent health limits for the more hazardous $\mathrm{PM}_{2.5}$ fraction [21]. The criteria pollutant program also regulates VOCs from certain sources because they are a precursor to the formation of ground-level ozone, another criteria pollutant. Ammonia is also a precursor pollutant, as it readily reacts with sulfate and nitric acid to form $\mathrm{PM}_{2.5}$ particles of ammonium sulfate and ammonium nitrate [5], but EPA does not currently regulate it directly.

NAAQS for criteria pollutants are used to develop state implementation plans to reduce criteria pollutants to allowable levels in the ambient air. Once the NAAQS are established, the states implement a permitting program applicable to emissions sources, including emissions restrictions calculated to ensure that airsheds in the state will attain compliance with the NAAQS [22]. New and modified sources of criteria pollutants that have the potential to emit more than the applicable major source threshold -250 tons per year, in the case of AFOs - are subject to CAA requirements to limit emissions [23]. The stringency of the requirements depends on whether the airshed is meeting or exceeding the NAAQS for the particular pollutant.

The CAA's New Source Performance Standards (NSPS) program establishes emissions rates for various industry sectors, but EPA has not established these limits for the AFO sector. EPA's Greenhouse Gas Reporting Program requires facilities that emit more than 25,000 tons of $\mathrm{CO}_{2}$ equivalent to report their emissions of key climate change pollutants to EPA annually, including methane and nitrous oxide, both of which are emitted by AFOs. However, because of EPA's emissions thresholds, the program requires only the very largest livestock operations to report their emissions [24].

EPA has failed to enforce virtually all air pollution requirements applicable to AFOs, with the result that knowledge regarding the industry's air emissions has remained limited. There is no established method for estimating emissions at the AFO level; as a result, many AFOs do not know if they are subject to regulation under federal clean air laws, and the agency has few tools in place to actually reduce emissions that threaten public health and the environment [14].

\section{EPA's National Air Emissions Monitoring Study}

Decades after the passage of the CAA, CERCLA, and EPCRA, EPA had very little information about the quantities and rates of AFO air emissions of pollutants of concern [4]. As the average size of livestock operations continued to expand across the USA [4], the question whether AFOs emit air pollutants in sufficient quantities to warrant federal regulation spurred the 2003 National Academy of Sciences (NAS) report Air Emissions from Animal Feeding Operations: Current Knowledge, Future Needs [2]. This report analyzed existing AFO emissions data and research, and it concluded, in part, with the recommendation that EPA create a process-based model of AFO emissions that incorporates mass balance constraints for nitrogen compounds, hydrogen sulfide, and methane, rather than following an emissions rate approach [2]. Such a model would be based on estimates of the movement of emissions-producing substances through various processes at the AFO, as opposed to approaches based on monitoring a facility deemed "representative" of similar sites or using monitoring data to establish equations that account for selected variables affecting emissions [2].

In 2005, EPA initiated a process the agency asserted would enable it to appropriately regulate air pollution emitted from AFOs, relying on an emissions study rather than the processbased model approach. EPA entered into an Air Compliance Agreement with AFO operators representing nearly 14,000 facilities throughout the country [14]; just $3 \%$ of the US Department of Agriculture's estimated 450,000 AFOs in the USA [25] but likely a much higher percentage of the approximately 20,000 largest AFOs that meet the definition of a concentrated AFO (CAFO) [26]. Air Compliance Agreement participants agreed to fund a national emissions study meant to develop EEMs capable of estimating AFO emissions and thereby enabling AFOs to comply with the CAA, CERCLA, and EPCRA. These AFOs paid penalties averaging approximately $\$ 2,500$ per facility into a fund, which then financed a 2-year National Air Emissions Monitoring Study (NAEMS) [14].

In exchange for this penalty and willingness to participate in monitoring, the AFOs received safe harbor from EPA enforcement for civil violations of the CAA, CERCLA, and EPCRA until EPA establishes AFO EEMs for most major livestock sectors [14]. As described below, EPA has not yet finalized EEMs, and so the safe harbor remains in effect. 
The Air Compliance Agreement set out a monitoring study protocol for collecting emissions data from AFOs deemed "representative" of their industry sector. Livestock industry organizations played a significant role in the design and implementation of the study. First, industry groups established a nonprofit organization, the Agricultural Air Research Council, to collect and distribute the funds for the study [14]. This Council then selected an independent monitoring contractor to oversee the budget and expenditures for the study. The Council also selected the study's Science Advisor, Dr. Al Heber of Purdue University, who designed the study and developed the Quality Assurance Project Plan (QAPP) for EPA approval. Finally, the Council developed the list of potential monitoring sites from the Air Compliance Agreement participants, which were selected considering geographic, climatic, and operational variables in an effort to represent many AFOs, as well as considering logistical factors, such as the proximity of the site to a study researcher [14]. The resulting list of study sites (Table 2) included 25 sites in nine states, as well as a broiler site monitored by Tyson Foods.
EPA's goal was to collect data sufficient to estimate emissions of ammonia, hydrogen sulfide, particulates, and VOCs from the hog, egg layer, meat bird, and dairy industries, taking into account variables such as climate, waste treatment type, and building ventilation type. Nonetheless, the agency approved a study plan to collect emissions from just a few sites per livestock sector, with no sites in some major livestockproducing states. Critics asserted that NAEMS was designed to fail and could not provide data capable of supporting EEM development for AFOs nationwide, but EPA did not reconsider its approach [4].

\section{NAEMS and EPA's Emissions Reporting Exemption}

EPA supported its grant of immunity from the CAA, CERCLA, and EPCRA by asserting that NAEMS would bring participants into compliance with applicable statutory requirements [19]. CERCLA and EPCRA continuous release reporting for all facilities emitting more than the RQ of
Table 2 National Air Emissions Monitoring Study (NAEMS)monitored animal feeding operations (AFOs)

\footnotetext{
${ }^{a}$ Data from the Kentucky site are from a study conducted by Tyson Foods [27]
}

\begin{tabular}{|c|c|c|c|c|}
\hline $\mathrm{AFO}$ & State & County & Site name & Type of operation monitored \\
\hline 1 & California & San Joaquin & CA1B & Broiler (barn) \\
\hline 2 & California & San Joaquin & $\mathrm{CA} 2 \mathrm{~B}$ & Egg layer (barn) \\
\hline 3 & California & San Joaquin & CA5B & Dairy (barn) \\
\hline 4 & Iowa & Marshall & IA4B & Swine (sow) (barn) \\
\hline 5 & Iowa & Jefferson & IA3A & Swine finisher (basin) \\
\hline \multirow[t]{2}{*}{6} & \multirow[t]{2}{*}{ Indiana } & \multirow[t]{2}{*}{ Wabash } & $\mathrm{IN} 2 \mathrm{~B}$ & Egg layer (barn) \\
\hline & & & $\mathrm{IN} 2 \mathrm{H}$ & High-rise barns \\
\hline 7 & Indiana & Carroll & IN3B & Swine finisher (barn) \\
\hline 8 & Indiana & Clinton & IN4A & Swine (sow) (lagoon) \\
\hline 9 & Indiana & Jasper & IN5B & Dairy (barn) \\
\hline 10 & Indiana & Jasper & IN5A & Dairy (lagoon) \\
\hline 11 & North Carolina & Nash & $\mathrm{NC} 2 \mathrm{~B}$ & Egg layer (barn) \\
\hline 12 & North Carolina & Duplin & $\mathrm{NC} 3 \mathrm{~B}$ & Swine finisher (barn) \\
\hline 13 & North Carolina & Bladen & $\mathrm{NC} 3 \mathrm{~A}$ & Swine finisher (lagoon) \\
\hline \multirow[t]{2}{*}{14} & \multirow[t]{2}{*}{ North Carolina } & \multirow[t]{2}{*}{ Duplin } & $\mathrm{NC} 4 \mathrm{~A}$ & Swine (sow) (lagoon) \\
\hline & & & $\mathrm{NC} 4 \mathrm{~B}$ & Swine (sow) (barn) \\
\hline 15 & New York & Onondaga & NY5B & Dairy (barn) \\
\hline 16 & Oklahoma & Texas & OK3A & Swine finisher (lagoon) \\
\hline \multirow[t]{2}{*}{17} & \multirow[t]{2}{*}{ Oklahoma } & \multirow[t]{2}{*}{ Texas } & OK4A & Swine (sow) (lagoon) \\
\hline & & & OK4B & Swine (sow) (barn) \\
\hline 18 & Texas & Deaf Smith & TX5A & Dairy (corral) \\
\hline \multirow[t]{2}{*}{19} & \multirow[t]{2}{*}{ Washington } & \multirow[t]{2}{*}{ Yakima } & WA5A & Dairy (basin) \\
\hline & & & WA5B & Dairy (barn) \\
\hline \multirow[t]{2}{*}{20} & \multirow[t]{2}{*}{ Wisconsin } & \multirow[t]{2}{*}{ Saint Croix } & WI5A & Dairy (lagoon) \\
\hline & & & WI5B & Dairy (barn) \\
\hline \multicolumn{5}{|c|}{ Also monitored } \\
\hline 21 & Kentucky $^{\mathrm{a}}$ & Union and Hopkins & KY1B & Broiler (barn) \\
\hline
\end{tabular}


ammonia or hydrogen sulfide were two of the primary applicable requirements under consideration.

Also in 2005, however, poultry industry groups approached EPA, seeking exemptions from CERCLA's and EPCRA's ammonia reporting requirements [28]. Despite the Air Compliance Agreement and the agency's plans to conduct NAEMS, EPA granted an even broader exemption by rulemaking in 2008, eliminating reporting requirements for all reportable pollutants from all AFOs under CERCLA, and all but large CAFOs (those over a certain size threshold, such as 2,500 hogs or 700 dairy cows, based generally on waste produced by sector) under EPCRA [29]. Several environmental organizations challenged this regulation's legality in court [30], arguing that it is contrary to the plain language of the statutes, which require all facilities emitting above the RQ of a listed pollutant to report. However, EPA requested a voluntary remand from the court for the opportunity to revisit the rule, which the court granted in 2010 without first ruling on the merits of the case [31]. As a result, EPA received the opportunity to reverse or amend the exemption rule without a court order dictating any specific action. The court declined to include a deadline in granting the remand, and EPA has yet to take action to address the exemption rule at the time of this writing.

While finalizing this exemption rule, NAEMS proceeded, which involved monitoring emissions of ammonia, hydrogen sulfide, VOCs, and PM from 25 sites from 2007 to 2009. Specifically, the study monitored ammonia, $\mathrm{PM}\left(\mathrm{PM}_{10}\right.$, $\mathrm{PM}_{2.5}$, and total suspended particulates [TSP]), hydrogen sulfide, and VOCs at confinement sources, and monitored ammonia, hydrogen sulfide, and VOCs from waste lagoons and basins. Under the Agreement, EPA was tasked with evaluating the NAEMS data and publishing draft EEMs within 18 months of the study's conclusion. Once EPA published the final EEMs, the agreement required participating AFOs to calculate their estimated emissions, determine whether they are in compliance with air pollution laws, and either bring their facilities into compliance or inform EPA that they are in compliance, as warranted [14].

In January 2011, EPA released the raw NAEMS data from the completed study and issued a Call for Information, requesting "quality-assured emissions and process data that are relevant to developing emissions estimating methodologies for animal feeding operations," which it would consider using to supplement the NAEMS data [32]. The agency received numerous peer-reviewed on-farm emissions studies and other documents in response [33]. These studies could significantly increase the size of EPA's overall data set and allow the agency to address variables with an impact on emissions but not captured in the small number of NAEMS sites for a given industry sector. For example, NAEMS included only a single broiler chicken site, in addition to a similar study of two Kentucky sites sponsored by Tyson Foods [34]. Thirty- six of the Call for Information submissions provided data related to broiler chicken emissions, including studies of ammonia and particulate emissions from broiler confinement buildings, using a variety of sampling methods [34].

\section{NAEMS Data Analysis}

In February 2012, EPA sent its draft EEMs for the broiler chicken sector and for open waste storage systems - hog and dairy basins and lagoons - to its Science Advisory Board Animal Feeding Operation Emission Review Panel (SAB) with charge questions for the panel to consider [35]. The questions sought the SAB's input on EPA's statistical methodology, treatment of zero and negative monitoring values, and use of extremely limited broiler VOC data. EPA then issued the draft EEMs for public comment in March 2012.

On the basis of data from the two broiler facilities monitored - the NAEMS site and the Tyson site-EPA created broiler EEMs for all of the pollutants addressed in the study. To increase the size of its data set and ensure that it represented all seasonal meteorological conditions that affect open source emissions, EPA combined its lagoon and basin data from the nine hog and dairy waste systems that were monitored. Although NAEMS monitored ammonia and hydrogen sulfide at open sources and called for VOC monitoring, EPA developed an open source EEM only for ammonia. EPA did not develop an EEM for hydrogen sulfide, but the agency said it was planning to develop one after receiving feedback on its ammonia draft. EPA never even received VOC data from these sources and was therefore unable to propose a VOC EEM. Despite these issues related to data completeness, the draft EEMs rely almost entirely on NAEMS data and reject most of the information from the studies EPA received in response to its Call for Information. While EPA did indicate that certain studies' data could be useful to assess the EEMs, the submitted studies' data were not incorporated into the development of the drafts themselves. EPA also indicated it will not use data from Call for Information studies if those studies used monitoring methodologies significantly different than NAEMS, because of difficulties in integrating the data sets [34].

In April 2013, EPA's SAB issued its final report in response to EPA's charge questions. The report was highly critical of the NAEMS design and methodology, the data generated, EPA's statistical approach, its treatment of the available data, and the resulting draft EEMs. In short, the SAB recommended that EPA go back to the drawing board and pursue a processbased emissions model capable of representing the chemical, biological, and physical processes that affect emissions, rather than continuing to develop statistical models based on combined data sets and predictor variables [36•]. The SAB asserted that EPA's NAEMS data are far too limited to create a model capable of predicting emissions from facilities 
beyond those monitored - much less all facilities in a given livestock sector nationwide. It further recommended that EPA use the NAEMS data to begin developing a simple processbased modeling approach. Subsequent research has similarly concluded that many variables affect AFO emissions of pollutants of concerns, and therefore numerous air emissions studies at various types of AFOs are necessary to create accurate EEMs [37]. EPA has not issued any additional or revised draft EEMs since.

Despite the SAB's critique, Science Advisor Al Heber has completed several analyses of data generated in NAEMS. One such 2011 study noted that despite an abundance of on-farm air emissions data, analytical barriers to integrating data into inventories persist; process-based models have their own drawbacks, such as the need to consider farm-level inputs for numerous variables and the complexity of AFO emissions [38]. Dr. Heber also completed industry-specific analyses of the NAEMS data for hog and egg layer industry organizations. These initial analyses used NAEMS data to estimate animal numbers that would exceed applicable requirements under the CAA, CERCLA, and EPCRA. They concluded that the only requirement that $\mathrm{AFO}$ emissions from sow and finishing hog confinement houses, as well as egg layer facilities, would likely trigger is the ammonia reporting requirement in CERCLA and EPCRA [39, 40]. It is worth noting, however, that these reports were drafted on behalf of the industry organizations whose members may face increased regulation, depending on the outcome of NAEMS, and who have an interest in finding that as few AFOs as possible are subject to federal regulation for their air pollution.

\section{Related Actions to Address Agricultural Air Pollution}

Public records obtained from EPA under the Freedom of Information Act (FOIA) indicate that EPA has made little progress incorporating the SAB's feedback into its EEM process or otherwise moving toward a final set of AFO EEMs [41]. This stalled process has also delayed EPA action with regard to other policy changes needed to address AFO air emissions. Four years after the court sent the emissions reporting exemption rule back to EPA for additional consideration, the agency has yet to act. EPA has indicated its intention of delaying action on the emissions reporting exemption rule until it concludes the EEM process [42], although the most straightforward action for the agency to take would be to simply reverse the rule, which does not need to include any emissions data or estimates.

EPA has also delayed its consideration of two pending petitions to regulate AFO emissions under two CAA programs, citing the EEM process as the rationale to postpone action. In 2009, the Humane Society of the United States (HSUS) petitioned EPA to list CAFOs as a source category under CAA Section 111, which establishes NSPS that limit an industry sector's hourly emissions rates of air pollutants [43]. In 2011, the Environmental Integrity Project (EIP) petitioned EPA to list ammonia as a CAA criteria pollutant and establish ambient air quality standards to protect public health and welfare, focusing on AFOs as an important source of ammonia pollution [44].

Documents recently obtained under FOIA and conversations with agency staff indicate that EPA has not taken any significant steps to consider either petition, and intends to wait until completing the EEMs to address them [45]. The NSPS petition would require restrictions on emissions rates, and EEMs would facilitate implementation of such restrictions; however, the petition addresses pollutants, such as methane, that are not monitored in NAEMS, calling into question EPA's strategy of postponing action on the petition until EEMs have been established. The ammonia petition asks EPA to establish health-based ambient standards for the pollutant regardless of the source, so the AFO EEM development process has no bearing on EPA's response. Nonetheless, final EEMs have been cited as a threshold requirement for EPA action on multiple issues related to AFO air emissions, and EPA's timetable for addressing AFO air emissions is increasingly protracted (Table 3).

Although EPA has not attempted to measure AFO greenhouse gas emissions through NAEMS or otherwise, the agency's 2009 greenhouse gas reporting rule does include livestock operations to a very limited extent [24]. This regulation requires emitters of carbon dioxide and other

Table 3 Significant recent actions related to animal feeding operation (AFO) air emissions regulation

\begin{tabular}{ll}
\hline Years & Action \\
\hline 2003 & NAS report calls for model to estimate AFO emissions \\
2005 & EPA enters Air Compliance Agreement with AFOs \\
$2007-2009$ & NAEMS monitoring takes place \\
2008 & EPA issues AFO CERCLA/EPCRA exemption rule \\
2009 & HSUS files CAFO NSPS petition \\
2010 & Court grants CERCLA/EPCRA exemption remand to EPA \\
2011 & EIP files ammonia CAA petition \\
2011 & EPA issues emissions data Call for Information \\
2012 & EPA issues Draft Broiler and Open Source EEMs \\
2013 & SAB issues report responding to draft EEMs and EPA \\
& questions
\end{tabular}

$C A A$ Clean Air Act, $C A F O$ concentrated animal feeding operation, CERCLA Comprehensive Environmental Response, Compensation, and Liability Act, EEM emissions estimating methodology, EIP Environmental Integrity Project, EPA Environmental Protection Agency, EPCRA Emergency Planning and Community Right-to-Know Act, HSUS Humane Society of the United States, NAEMS National Air Emissions Monitoring Study, NAS National Academy of Sciences, NSPS New Source Performance Standards, $S A B$ Science Advisory Board Animal Feeding Operation Emission Review Panel 
greenhouse gases, including methane and nitrous oxide, to report those emissions to EPA if they exceed 25,000 metric tons of $\mathrm{CO}_{2}$ equivalent per year. As a result, only the very largest AFOs in the USA - such as hog confinements with an annual average population exceeding 34,100 hogs - are required to report. Rather than deriving its own emissions factors or creating a process-based model for these pollutants, EPA relied on the existing Intergovernmental Panel on Climate Change, US Department of Agriculture, and American Society of Agricultural and Biological Engineers for default nitrous oxide and methane emissions values from various livestock sectors [24].

Although EPA has not finalized the EEMs or taken other action to increase regulation of AFO air emissions, Congress acted in 2013 and in 2014 to block certain EPA expenditures to do so. The 2014 Consolidated Appropriations Bill prohibited any appropriated funds from being "used to promulgate or implement any regulation requiring the issuance of permits under title V of the Clean Air Act (42 U.S.C. 7661 et seq.) for carbon dioxide, nitrous oxide, water vapor, or methane emissions resulting from biological processes associated with livestock production" or from being "used to implement any provision in a rule, if that provision requires mandatory reporting of greenhouse gas emissions from manure management systems" [46]. The 2015 Appropriations Bill contains identical language [47]. Consequently, EPA has been barred from spending any money to enforce even the limited greenhouse gas reporting requirements in place for very large livestock operations. EPA has therefore not been able to make AFO emissions reports available online with its other greenhouse gas reporting data, but any existing reports may be available under FOIA.

\section{Conclusions}

EPA's reliance on NAEMS, which had many built-in limitations and generated significantly less high-quality data than had been promised, has delayed important agency actions to protect public health and the environment from AFO air emissions. EPA should take all necessary steps to establish scientifically defensible estimates of AFO air pollution, including consideration of peer-reviewed published emissions studies. If EPA is unable to establish EEMs by using available data, it should consider pursuing the development of a process-based model with broader applicability than its initial modeling approach. However, the EEM process is not a scientific or regulatory prerequisite to several other EPA actions, such as action to reverse the 2008 emissions reporting exemption rule and determinations in response to two pending petitions to regulate $\mathrm{AFO}$ emissions under the CAA. EPA action to estimate and regulate AFO greenhouse gas emissions is also independent of the EEM process, as NAEMS did not consider these pollutants. Congressional action to restore EPA's full regulatory authority is necessary if the agency is to fulfill its public health mandate; however, there are numerous actions EPA can currently take, and it has put forth no compelling reasons for delay.

\section{Compliance with Ethics Guidelines}

Conflict of Interest Tarah Heinzen declares that she has no conflict of interest.

Human and Animal Rights and Informed Consent This article does not contain any studies with human or animal subjects performed by the author.

\section{References}

Papers of particular interest, published recently, have been highlighted as:

- Of importance

1. US Department of Agriculture, National Agricultural Statistics Service. 2012

2. National Research Council, Ad Hoc Committee on Air Emissions from Animal Feeding Operations, Committee on Animal Nutrition, Board on Agriculture and Natural Resources, Board on Environmental Studies and Toxicology, Division on Earth and Life Studies, Air Emissions from Animal Feeding Operations: Current Knowledge, Future Needs. 2003.

3. Mubarak H, Johnson TG, Miller KK The impacts of animal feeding operations on rural land values. Report R-99-02, College of Agriculture, Food and Natural Resources, University of MissouriColumbia. 1999.

4. Claudia Copeland, Cong. Research Serv., RL 32948, Air Quality Issues and Animal Agriculture: A Primer 1. 2010.

5. Pinder RW et al. Environmental impact of atmospheric $\mathrm{nh}_{3}$ emissions under present and future conditions in the Eastern United States. Geophys Res Lett. 2008;35:L12808.

6. Paulot F, Jacob D. Hidden cost of US agricultural exports: particulate matter from ammonia emissions. Environ Sci Technol. 2013;48:903-8.

7. Parker DB et al. Effect of wind tunnel air velocity on VOC flux from standard solutions and CAFO manure/wastewater. Am Soc Agric Biol Eng. 2010;53(3):831.

8. EPA. Ground Level Ozone, http://www.epa.gov/groundlevelozone/.

9. Pew Commission on Industrial Farm Animal Production. Putting meat on the table: industrial farm animal production in America. 2008.

10. EPA. Toxicological Review of Ammonia (CASRN 7664-417) In Support of Summary Information on the Integrated Risk Information System (IRIS), Revised External Review Draft. 2013.

11. EPA. Toxicological Review of Hydrogen Sulfide (CAS No. 778306-4) In Support of Summary Information on the Integrated Risk Information System (IRIS) 2003.

12. United Nations Food and Agriculture Organization. Tackling climate change through livestock: a global assessment of emissions and mitigation opportunities. 2013. 
13. Eshel G, Shepon A, Makov T, et al. Land, irrigation water, greenhouse gas, and reactive nitrogen burdens of meat, eggs, and dairy production in the United States. Proc Natl Acad Sci U S A. 2014. doi:10.1073/pnas.1402183111.

14. EPA. Animal feeding operations consent agreement and final order, 70 Fed. Reg. 4958 (Jan. 31, 2005).

15. 42 U.S.C. $\S 9603 ; 42$ U.S.C. $§ 11004$.

16. 40 C.F.R. $\S \S 302,355$, App. A to $\S 355$.

17. 42 U.S.C. $\S 11044$.

18. Smith T, Rubenstein L, Nachman K. Availability of information about airborne hazardous releases from animal feeding operations. PLoS One. 2013;8(12):1.

19. 42 U.S.C. $\S \S 7408-7409$.

20. 42 U.S.C. $\S 7602(\mathrm{~h})$.

21. EPA. National Ambient Air Quality Standards (NAAQS), http:// www.epa.gov/air/criteria.html.

22. 42 U.S.C. $\S 7410$.

23. 40 C.F.R. $\$ 52.21(b)(1)(i)$.

24. EPA. Mandatory Reporting of Greenhouse Gases, 74 Fed. Reg. 56374 (Oct. 30, 2009); 40 C.F.R. § 98, Subpart JJ.

25. USDA Natural Resources Conservation Service, Animal Feeding Operations, http://www.nrcs.usda.gov/wps/portal/nrcs/main/ national/plantsanimals/livestock/afo/.

26. EPA. National Pollutant Discharge Elimination System (NPDES) Concentrated Animal Feeding Operation (CAFO) Reporting Rule, 76 Fed. Reg. 65431, 65445 (Oct. 21, 2011).

27. EPA. Monitored AFOs, http://www.epa.gov/airquality/ agmonitoring/data.html.

28. Letter from George Watts et al., Pres. Nat'l Chicken Council, to EPA Administrator Stephen L. Johnson, Docket ID EPA-HQSFUND-2005-0013-0002 (Aug. 5, 2005).

29. EPA. CERCLA/EPCRA Administrative Reporting Exemption for Air Releases of Hazardous Substances From Animal Waste at Farms, 73 Fed. Reg. 76,948, 76,951 (Dec. 18, 2008).

30. Waterkeeper Alliance v. EPA, D.C. Cir., No. 09-1017 (Jan. 15, 2009).

31. Order, Waterkeeper Alliance v. EPA, D.C. Cir., No. 09-1017 (Oct. 19, 2010).

32. EPA. Call for Information: Information Related to the Development of Emission-Estimating Methodologies for Animal Feeding Operations, 76 Fed. Reg. 3060, 3060 (Jan. 19, 2011).

33. EPA. Animal Feeding Operations Emissions Estimating Methodologies Docket Comments, ID EPA-HQ-OAR-2010-0960 (Jan. 19, 2011).
34. EPA. Development of Emissions-Estimating Methodologies for Broiler Operations (Draft); EPA, Development of Emissions Estimating Methodologies for Lagoons and Basins at Swine and Dairy Animal Feeding Operations (Draft) (Feb. 2012).

35. EPA. Memorandum from Stephen D. Page to Ed Hanlon, Animal Feeding Operations Air Emissions Estimating Methodologies from the National Air Emissions Monitoring Study (Feb. 17, 2012).

36. Science Advisory Board Animal Feeding Operation Emission Review Panel, Apr. 19, 2013. SAB Review of EmissionsEstimating Methodologies for Broiler Animal Feeding Operations and for Lagoons and Basins at Swine and Dairy Animal Feeding Operations, EPA-SAB-13-003. This report provides an extensive analysis of EPA's methodology and results.

37. James KM, Blunden J, Rumsey IC, et al. Characterizing ammonia emissions from a commercial mechanically ventilated swine finishing facility and an anaerobic waste lagoon in North Carolina. Atmos Pollut Res. 2012;3:279-88.

38. Ni J, Cortus EL, Heber AJ. Improving ammonia emission modeling and inventories by data mining and intelligent interpretation of the national air emission monitoring study database. Atmosphere. 2011;2:110-28.

39. Heber AJ, Grant RA, Boehm M, Cortus EL, Bogan BW, Lim TT, et al. 2010. Evaluation and analysis of NAEMS Pork Data. Final Report. Purdue University, West Lafayette, IN, November 15.

40. Heber AJ, Ni J-Q, Bogan BW, Cortus EL, Kilic I, Zhang R, et al. 2012. Evaluation and Analysis of NAEMS Layer Data. Final Report. Purdue University, West Lafayette, IN, February 29.

41. Freedom of Information Act response documents on file with EIP.

42. Discussions between environmental organizations and EPA staff (Mar. 24, 2011).

43. The Humane Society of the US et al. Petition to List Concentrated Animal Feeding Operations under Clean Air Act Section 111(b)(1)(A) of the Clean Air Act, and to Promulgate Standards of Performance under Clean Air Act Sections 111(b)(1)(B) and 111(d). 2009.

44. Environmental Integrity Project et al. Petition for the Regulation of Ammonia as a Criteria Pollutant Under Clean Air Act Sections 108 and 109. 2011.

45. EIP teleconference with EPA staff (Jul. 9, 2013).

46. Consolidated Appropriations Act, 2014, H.R. 3547, 113th Cong. 2014.

47. Consolidated and Further Continuing Appropriations Act, 2015, H.R. 83, 113th Cong. 2014). 